\title{
Some Fixed Point Theorems on Meir Keeler Type under Strict Contractions
}

\author{
Rajeshri Rana \\ Asst. Prof. \\ Applied Science and \\ Humanities Department \\ G.B.Pant Engineering College, \\ Pauri 246001, India
}

\author{
R. C. Dimri \\ Professor \\ Department of Mathematics \\ Birla Campus, \\ H. N. B. Garhwal Central Univ., \\ Srinagar-Garhwal, India.
}

\author{
Anita Tomar \\ Asst. Prof. \\ Department of Mathematics \\ Govt. Degree College \\ Dakpathar, Vikasnagar, \\ Dehradun, India.
}

\begin{abstract}
This paper explores the common fixed point theorems involving two pairs of weakly compatible mappings. Also the property (E.A) is proved under a new contractive condition which is independent of the previous known contractive definitions.
\end{abstract}

\section{Keywords:}

Common fixed point, Compatible and Compatible mappings of type (A), (B), (C) and (P), Weakly compatible maps, property E.A.

\section{INTRODUCTION}

The study of common fixed point of mappings satisfying contractive type of conditions has emerged as a very active field of research activity during recent years. The most general form of the common fixed point theorem pertaining to four mappings $\mathrm{A}, \mathrm{B}, \mathrm{S}$ and $\mathrm{T}$ of a metric space $(\mathrm{X}, \mathrm{d})$ uses either a Banach type contractive condition if the form

$\mathrm{d}(\mathrm{Ax}, \mathrm{By}) \leq \mathrm{kM}(\mathrm{x}, \mathrm{y}) ; \quad 0 \leq \mathrm{k}<1$

where $M(x, y)=\max \{d(S x, T y), d(A x, S x), d(B y, T y)$,

$$
[\mathrm{d}(\mathrm{Sx}, \mathrm{By})+\mathrm{d}(\mathrm{Ax}, \mathrm{Ty})] / 2\}
$$

or a Meir Keeler type $(\varepsilon, \delta)$ contractive condition, that is given $\varepsilon>0$, there exists $\delta>0$ such that

$$
\varepsilon<\mathrm{M}(\mathrm{x}, \mathrm{y})<\varepsilon+\delta \Rightarrow \mathrm{d}(\mathrm{Ax}, \mathrm{Ay}) \leq \varepsilon
$$

or a $\psi$ contractive condition of the form

$(\mathrm{Ax}, \mathrm{Ay}) \leq \psi(\mathrm{M}(\mathrm{x}, \mathrm{y}))$

involving a contractive gauge function $\psi:[0, \infty) \rightarrow[0, \infty)$ such that $\psi(\mathrm{t})<\mathrm{t}$ for each $\mathrm{t}>0$.

Clearly Banach type contractive condition is a special case of both Meir Keeler $(\varepsilon, \delta)$ contractive and $\psi$ contractive conditions. As $\psi$ contractive type of condition does not guarantee the existence of fixed point unless some additional condition is assumed. So various authors have introduced different conditions on $\psi$ (i) $\quad \psi(\mathrm{t})$ is non decreasing and $t /(t-f(t))<0$ for every t > 0. (Carbone et al. [6])

(ii) $\quad \psi(\mathrm{t})$ is non decreasing, for each $\mathrm{t}>0, \lim _{n \rightarrow \infty} \psi^{n}(t)=0$ which implies that $\quad \psi(\mathrm{t})<\mathrm{t}$. (Jachymski [7])

(iii) $\psi(\mathrm{t})$ is upper semi continuous (Boyd and Wong [5], Jachymski [7], Pant[16])

(iv) $\psi(\mathrm{t})$ is non decreasing, right continuous and $\psi(\mathrm{t})<\mathrm{t}$ for every $\mathrm{t}>0$. ( Park and Rhoades[19])

Besides this, we have deduction from Pant et al. [18] than a $(\varepsilon, \delta)$ contractive type of condition (1.2) neither assures the existence of fixed point nor implies an analogous $\psi$ contractive condition (1.3). As a result of it two types of contractive conditions (1.2) and (1.3) are independent of each other thus to ensure the existence of common fixed point under contractive type of condition (1.2), $\delta$ takes on following conditions, used by various authors:

(v) $\delta$ is non decreasing. (Pant [16])

(vi) $\delta$ is lower semi continuous (Jungck [10], Jungck et al. [17])

It follows therefore that the known common fixed point theorems can be extended and generalized if instead of assuming one of the contractive condition (1.2) or (1.3) with additional conditions on $\delta$ and $\psi$, we assume contractive condition (1.2) together with the following condition of the form:

$$
\begin{array}{r}
d A x, B y<\max \left\{\alpha_{1}[d S x, T y+d A x, S x+d B y, T y],\right. \\
\left.\alpha_{2}[d S x, B y+d A x, T y] / 2\right\}
\end{array}
$$

for $0 \leq \alpha_{1}<1,1 \leq \alpha_{2}<2$

In this paper, we have proved the common fixed point theorems for four mappings adopting this approach. 


\section{PRELIMINARIES}

Let $S$ and $T$ be the self mappings of a metric space (X, d), S and T are commuting if ST $x=\mathrm{TS} x$ for all $x \in \mathrm{X}$. According to definition of Sessa [23], $\mathrm{S}$ and $\mathrm{T}$ are defined to be weakly commuting if for all $x \in \mathrm{X}$.

$\mathrm{d}(\mathrm{ST} x, \mathrm{TS} x) \leq \mathrm{d}(\mathrm{T} x, \mathrm{~S} x)$

Any two self maps of a metric space (X, d) are defined as compatible by Jungck [10], if

$$
\lim _{n \rightarrow \infty} \mathrm{d}\left(\operatorname{ST} x_{n}, \operatorname{TS} x_{n}\right)=0
$$

Whenever $\left\{x_{n}\right\}$ is a sequence in $\mathrm{X}$, such that $\lim _{n \rightarrow \infty} \mathrm{S} x_{n}=$ $\lim \mathrm{T} x_{n}=\mathrm{t}$ for some $\mathrm{t} \in \mathrm{X}$. Jungck [10] defined compatibility as generalization of commutativity and weak commutativity.

The commuting maps imply weakly commuting which on other hand implies compatibility. These are verified by examples given in literature. See [10] and [24]

Jungck et al. [12] defined pair $\{\mathrm{S}, \mathrm{T}\}$ of self maps of metric space $(X, d)$ as compatible of type $A$ if

$$
\lim _{n \rightarrow \infty} \mathrm{d}\left(\operatorname{ST} x_{n}, \mathrm{~T}^{2} x_{n}\right)=0 \text { and } \lim _{n \rightarrow \infty} \mathrm{d}\left(\operatorname{ST} x_{n}, \mathrm{~S}^{2} x_{n}\right)=0
$$

whenever $\left\{x_{n}\right\}$ is a sequence in $\mathrm{X}$, such that $\lim _{n \rightarrow \infty} \mathrm{S} x_{n}=$ $\lim _{n \rightarrow \infty} \mathrm{T} x_{n}=\mathrm{t}$ for some $\mathrm{t} \in \mathrm{X}$.

Clearly weakly commuting implies compatible of type (A). but by [12] its converse is not true.

Pathak and Khan [20] defined the $S$ and $T$ to be compatible mapping of type (B) as a generalization of compatible mappings of type (A) if

$$
\lim _{n \rightarrow \infty} d\left(T S x_{n}, S S x_{n}\right) \leq \frac{1}{2}\left[\lim _{n \rightarrow \infty} d\left(T S x_{n}, T t\right)+\lim _{n \rightarrow \infty} d\left(T t, T T x_{n}\right)\right]
$$

and

$$
\lim _{n \rightarrow \infty} d\left(S T x_{n}, T T x_{n}\right) \leq \frac{1}{2}\left[\lim _{n \rightarrow \infty} d\left(S T x_{n}, S t\right)+\lim _{n \rightarrow \infty} d\left(S t, S S x_{n}\right)\right]
$$

whenever $\left\{x_{n}\right\}$ is a sequence in $\mathrm{X}$, such that $\lim _{n \rightarrow \infty} \mathrm{S} x_{n}=$ $\lim _{n \rightarrow \infty} \mathrm{T} x_{n}=\mathrm{t}$ for some $\mathrm{t} \in \mathrm{X}$.

The compatible mappings of type (A) are compatible of type (B), but its converse is not true. See [10]. However compatibility of type (A) and compatibility of type (B) are equivalent if $\mathrm{S}$ and $\mathrm{T}$ are given continuous.

Pathak et.al. [21] defined selfmaps $\mathrm{S}$ and $\mathrm{T}$ of metric space $(X, d)$ as compatible mapping of type $(P)$ if

$\lim _{n \rightarrow \infty} \mathrm{d}\left(\operatorname{SS} x_{n}, \operatorname{TT} x_{n}\right)=0$

whenever $\left\{x_{n}\right\}$ is a sequence in $\mathrm{X}$, such that $\lim _{n \rightarrow \infty} \mathrm{S} x_{n}=$ $\lim _{n \rightarrow \infty} \mathrm{T} x_{n}=\mathrm{t}$ for some $\mathrm{t} \in \mathrm{X}$.

Again compatibility of type (A) and compatibility of type (P) are equivalent if S and T are given continuous, See [21].
Pathak et.al. [22] defined self maps $\mathrm{S}$ and $\mathrm{T}$ of metric space (X, d) to be compatible mapping of type (C), as generalization of compatible mappings of type (A) if

$$
\begin{aligned}
\lim _{n \rightarrow \infty} d\left(T S x_{n}, S S x_{n}\right) \leq \frac{1}{3}\left[\lim _{n \rightarrow \infty} d(\right. & \left.T S x_{n}, T t\right)+\lim _{n \rightarrow \infty} d\left(T t, S S x_{n}\right) \\
+ & \left.\lim _{n \rightarrow \infty} d\left(T t, T T x_{n}\right)\right] \text { and }
\end{aligned}
$$

$\lim _{n \rightarrow \infty} d\left(S T x_{n}, T T x_{n}\right) \leq \frac{1}{3}\left[\lim _{n \rightarrow \infty} d\left(S T x_{n}, S t\right)+\lim _{n \rightarrow \infty} d\left(S t, T T x_{n}\right)\right.$

$\left.+\lim _{n \rightarrow \infty} d\left(S t, S S x_{n}\right)\right]$

whenever $\left\{x_{n}\right\}$ is a sequence in $\mathrm{X}$, such that $\lim _{n \rightarrow \infty} \mathrm{S} x_{n}=$ $\lim _{n \rightarrow \infty} \mathrm{T} x_{n}=\mathrm{t}$ for some $\mathrm{t} \in \mathrm{X}$.

So, we see that compatibility of type (A) and compatibility of type (C) are equivalent if S and T are continuous. See [14].

Definition 1. [14] S and T are said to be weakly compatible if they commute at their coincidence points i.e. if $\mathrm{S} t=\mathrm{T} t$ for some $t$ $\in \mathrm{X}$ then $\mathrm{ST} t=\mathrm{TS} t$.

Lemma 1. [10, 12, 20, 21 and 22] If $S$ and $T$ are compatible, or compatible of type (A) or compatible of type (P), or compatible of type (B), or compatible of type (C), then they are weakly compatible.

The following example shows that converse is not true;

Example 1. Let $X=[0,20]$ with usual metric. Defined S, T: $X$ $\rightarrow \mathrm{X}$ by

$$
\begin{aligned}
& \mathrm{Sx}=\left\{\begin{array}{ll}
0 & \text { if } x=0 \\
x+15 & \text { if } 0<x \leq 5 \\
x-5 & \text { if } 5<x \leq 20
\end{array}\right. \text { and } \\
& \mathrm{Tx}=\left\{\begin{array}{l}
0 \text { if } x \in\{0\} \cup\{5,20] \\
3 \text { if } 0<x \leq 5
\end{array}\right.
\end{aligned}
$$

Let $x_{n}$ be the sequence defined by $x_{n}=5+\frac{1}{n}, \mathrm{n} \in \mathrm{N}$, then

$$
\mathrm{S} x_{n}=x_{n}-5 \rightarrow 0, \quad \mathrm{~T} x_{n}=0 \rightarrow 0 \text {. }
$$

As $n \rightarrow \infty, \mathrm{S}(0)=0=\mathrm{T}(0)$ and $\mathrm{ST}(0)=0=\mathrm{TS}(0)$

Clearly $\mathrm{S}$ ant $\mathrm{T}$ are weakly compatible maps, since they commute at their coincidence point $\mathrm{t}=0$. On other hand, we have

$$
\begin{aligned}
& \text { ST } x_{n}=\mathrm{S}(0)=0, \quad \text { SS } x_{n}=\mathrm{S}\left(x_{n}-5\right)=x_{n}+10 \\
& \text { TS } x_{n}=\mathrm{T}\left(x_{n}-5\right)=3 \quad \text { TT } x_{n}=\mathrm{T}(0)=0 .
\end{aligned}
$$

Consequently $\lim _{n \rightarrow \infty} \mid \operatorname{ST} x_{n}$ - TS $x_{n} \mid=3 \neq 0$ that proves S and T are not compatible. Moreover we have $\lim _{n \rightarrow \infty}\left|\operatorname{TS} x_{n}-\operatorname{SS} x_{n}\right|=$ $\lim _{n \rightarrow \infty}\left|3-x_{n}-10\right|=12 \neq 0$ 
Thus $\mathrm{S}$ and $\mathrm{T}$ are not compatible of type (A). Furthermore,

$$
\begin{aligned}
12=\lim _{n \rightarrow \infty}\left|\operatorname{TS} x_{n}-\operatorname{SS} x_{n}\right| \leq & \frac{1}{2}\left[\lim _{n \rightarrow \infty}\left|\operatorname{TS} x_{n}-\mathrm{Tt}\right|\right. \\
& \left.+\lim _{n \rightarrow \infty} \mid \text { Tt- TT } x_{n} \mid\right]=\frac{3}{2}
\end{aligned}
$$

So, $12 \measuredangle \frac{3}{2}$ which shows that $\mathrm{S}$ and $\mathrm{T}$ are not compatible of type (B).

$$
\begin{aligned}
\text { Again } 12= & \lim _{n \rightarrow \infty}\left|\operatorname{TS} x_{n}-\operatorname{SS} x_{n}\right| \not \frac{1}{3}\left[\lim _{n \rightarrow \infty}\left|\operatorname{TS} x_{n}-\mathrm{Tt}\right|\right. \\
& \left.\lim _{n \rightarrow \infty}\left|\mathrm{Tt}-\operatorname{SS} x_{n}\right|+\lim _{n \rightarrow \infty}\left|\mathrm{Tt}-\mathrm{TT} x_{n}\right|\right]=\frac{18}{6}=3
\end{aligned}
$$

Thus, $12 \not 3$, which shows that $S$ and $\mathrm{T}$ are not compatible of type (C). Also we have

$$
\lim _{n \rightarrow \infty} \mid \operatorname{SS} x_{n} \text { - TT } x_{n} \mid=15 \neq 0
$$

therefore $\mathrm{S}$ and $\mathrm{T}$ are not compatible of type $(\mathrm{P})$.

Property (E.A) [1]. Let A and S be two self maps of a metric space $(\mathrm{X}, \mathrm{d})$, then they are said to satisfy property (E.A.), if there exists a sequence $\left\{x_{n}\right\}$ in $\mathrm{X}$, such that $\lim _{n \rightarrow \infty} \mathrm{A} x_{n}=\lim _{n \rightarrow \infty} \mathrm{S} x_{n}$ $=\mathrm{t}$, for some $\mathrm{t} \in \mathrm{X}$.

If two maps are noncompatible, then they satisfy the property (E.A). However, its converse is not true. To support our assertion, we quote some examples from [1].

Example 2 ([1]). Let $X=[0, \infty)$. Define T, $S: X \rightarrow X$ by

$$
\mathrm{Tx}=\frac{x}{4}, \quad \mathrm{Sx}=\frac{3 x}{4}, \forall \mathrm{x} \in \mathrm{X} .
$$

Consider the sequence $\left\{x_{n}\right\}=\frac{1}{n}$. Clearly $\lim _{n \rightarrow \infty} \mathrm{T} x_{n}=\lim _{n \rightarrow \infty}$ $\mathrm{S} x_{n}=0$. Then $\mathrm{T}$ and $\mathrm{S}$ satisfy property (E.A).

Example 3 ([1]). Let $X=[2, \infty)$. Define $T, S: X \rightarrow X$ by

$\mathrm{Tx}=\mathrm{x}+1, \quad \mathrm{Sx}=2 \mathrm{x}+1, \forall \mathrm{x} \in \mathrm{X}$.

Suppose that property (E.A.) holds; then there exists in $\mathrm{X}$ a sequence $\left\{x_{n}\right\}$ satisfying

$$
\begin{aligned}
& \lim _{n \rightarrow \infty} \mathrm{A} x_{n}=\lim _{n \rightarrow \infty} \mathrm{S} x_{n}=\mathrm{t} \text {, for some } \mathrm{t} \in \mathrm{X} . \\
& \text { Therefore, } \lim _{n \rightarrow \infty} x_{n}=\mathrm{t}-1 \text { and } \lim _{n \rightarrow \infty} x_{n}=\frac{(t-1)}{2} . \text { Then }
\end{aligned}
$$
$\mathrm{t}=1$, which is a contradiction since $1 \notin \mathrm{X}$. Hence, $\mathrm{T}$ and $\mathrm{S}$ do not satisfy property E.A.

Lemma 2. (Jachymski [7]) Let $A, B, S$ and $T$ be self mappings of a metric space $(\mathrm{X}, d)$, such that $A(X) \subset \mathrm{T}(\mathrm{X})$, $B(X) \subset S(X)$. Assume further that for given $\varepsilon>0$ there exists $\delta>0$ such that for all $x, y$ in $X$.

$$
\varepsilon<\mathrm{M}(\mathrm{x}, \mathrm{y})<\varepsilon+\delta \Rightarrow \mathrm{d}(\mathrm{Ax}, \mathrm{By}) \leq \varepsilon
$$

and $\mathrm{d}(\mathrm{Ax}, \mathrm{By})<\mathrm{M}(\mathrm{x}, \mathrm{y})$ whenever $\mathrm{M}(\mathrm{x}, \mathrm{y})>0$

where

$M(x, y)=\max \{d(S x, T y), d(A x, S x), d(B y, T y),[d(S x, B y)+$ $\mathrm{d}(\mathrm{Ax}, \mathrm{Ty})] / 2\}$

Then for each $x_{0}$ in $X$, the sequence $\left\{y_{n}\right\}$ in $X$ is defined by the rule $\mathrm{y}_{2 \mathrm{n}}=\mathrm{Ax}_{2 \mathrm{n}}=\mathrm{Tx}_{2 \mathrm{n}+1}, \mathrm{y}_{2 \mathrm{n}+1}=\mathrm{Bx}_{2 \mathrm{n}+1}=\mathrm{Sx}_{2 \mathrm{n}+2}$ is a Cauchy sequence.

\section{MAIN RESULTS}

Theorem 1. Let $\mathrm{A}, \mathrm{B}, \mathrm{S}$ and $\mathrm{T}$ be the self maps defined on a metric space $(X, d]$ satisfying the following conditions:

(1) $\mathrm{Ax} \subset \mathrm{Tx}, \mathrm{Bx} \subset \mathrm{Sx}$

(2) Given $\varepsilon>0$, there exists a $\delta>0$ such that for all $\mathrm{x}, \mathrm{y}$ in $\mathrm{X}$,

$\varepsilon \leq \mathrm{M}(\mathrm{x}, \mathrm{y})<\varepsilon+\delta \Rightarrow \mathrm{d}(\mathrm{Ax}, \mathrm{By})<\varepsilon$ and (3.2)

(3) $d A x, B y<\max \left\{\alpha_{1}[S x, T y+d A x, S x+d B y, T y]\right.$

$$
\left.\alpha_{2}[d S x, B y+d A x, T y]\right\}
$$

for $0 \leq \alpha_{1}<1, \quad 1 \leq \alpha_{2}<2$

If one of $\mathrm{A}(\mathrm{x}), \mathrm{B}(\mathrm{x}), \mathrm{S}(\mathrm{x})$ or $\mathrm{T}(\mathrm{x})$ is a complete subspace of $\mathrm{X}$, then

\section{(I) $\quad \mathrm{A}$ and $\mathrm{S}$ have a coincidence \\ (II) $\mathrm{B}$ and $\mathrm{T}$ have coincidence}

Moreover, if A and S, as well as, B and T are weakly compatible, then $\mathrm{A}, \mathrm{B}, \mathrm{S}$ and $\mathrm{T}$ have a unique common fixed point.

Proof: Let $x_{0} \in \mathrm{X}$ be any arbitrary point of X. From (3.1), we can construct a sequence $\left\{\mathrm{y}_{\mathrm{n}}\right\}$ in $\mathrm{X}$ as follows

$\mathrm{y}_{2 \mathrm{n}}=\mathrm{Ax}_{2 \mathrm{n}}=\mathrm{Tx}_{2 \mathrm{n}+1}$ and $\mathrm{y}_{2 \mathrm{n}+1}=\mathrm{Sx}_{2 \mathrm{n}+2}=\mathrm{Bx}_{2 \mathrm{n}+1}$,

$$
n=0,1,2, \ldots \ldots \ldots \ldots \ldots
$$

Suppose $d\left(y_{2 n}, y_{2 n+1}\right)=0$ for some $n$. Then $y_{2 n}=y_{2 n+1}$ implies that $\mathrm{Ax}_{2 \mathrm{n}}=\mathrm{T}_{2 \mathrm{n}+1}=\mathrm{Bx}_{2 \mathrm{n}+1}=\mathrm{S} \mathrm{x}_{2 \mathrm{n}+2}$ and $\mathrm{T}$ and $\mathrm{B}$ have a coincidence point. Further if $d\left(y_{2 n+1}, y_{2 n+2}\right)=0$ for some $n$ then $A x_{2 n+2}=T$ $\mathrm{x}_{2 \mathrm{n}+3}=\mathrm{Bx}_{2 \mathrm{n}+1}=\mathrm{S} \mathrm{x}_{2 \mathrm{n}+2}$ and $\mathrm{A}$ and $\mathrm{S}$ have a coincidence point.

Moreover if we assume that $\mathrm{d}\left(\mathrm{y}_{\mathrm{n}}, \mathrm{y}_{\mathrm{n}+1}\right) \neq 0$ for each $\mathrm{n}$, then we have $\mathrm{M}(\mathrm{x}, \mathrm{y})>0$, otherwise $\mathrm{d}\left(\mathrm{y}_{\mathrm{n},}, \mathrm{y}_{\mathrm{n}+1}\right)=0 \quad$ (3.5) which is a contradiction.

We now show that $\left\{y_{n}\right\}$ is a Cauchy sequence. For this it is sufficient to show that $\left\{y_{2 n}\right\}$ is a Cauchy sequence. Suppose that $\left\{y_{2 n}\right\}$ is a Cauchy sequence. Then there exists $\in>0$, such that for each even integer $2 k$, there exists even integers $2 m(k)>2 n(k)$ $>2 \mathrm{k}$ such that $\mathrm{d}\left(\mathrm{y}_{2 \mathrm{n}(\mathrm{k})}, \mathrm{y}_{2 \mathrm{~m}(\mathrm{k})}\right) \geq \in$

For every even integer $2 \mathrm{k}$, let $2 \mathrm{~m}(\mathrm{k})$ be the least positive integer exceeding $2 \mathrm{n}(\mathrm{k})$ satisfying (3.6) such that

$$
\mathrm{d}\left(\mathrm{y}_{2 \mathrm{n}(\mathrm{k})}, \mathrm{y}_{2 \mathrm{~m}(\mathrm{k})-2}\right)<\epsilon
$$

Further $\delta>0 \Rightarrow \mathrm{d}\left(\mathrm{y}_{2 \mathrm{n}(\mathrm{k})}, \mathrm{y}_{2 \mathrm{~m}(\mathrm{k})}\right) \leq \mathrm{d}\left(\mathrm{y}_{2 \mathrm{n}(\mathrm{k})}, \mathrm{y}_{2 \mathrm{~m}(\mathrm{k})-2}\right)+\mathrm{d}_{2 \mathrm{~m}(\mathrm{k})-2}+$

Then by (3.5), (3.6) and (3.7) it follows that

$$
\lim _{n \rightarrow \infty} \mathrm{d}\left(\mathrm{y}_{2 \mathrm{n}(\mathrm{k})}, \mathrm{y}_{2 \mathrm{~m}(\mathrm{k})}\right)=\delta
$$

Also, using triangular inequality

$$
\left|\mathrm{d}\left(\mathrm{y}_{2 \mathrm{n}(\mathrm{k})}, \mathrm{y}_{2 \mathrm{~m}(\mathrm{k})-1}\right)-\mathrm{d}\left(\mathrm{y}_{2 \mathrm{n}(\mathrm{k})}, \mathrm{y}_{2 \mathrm{~m}(\mathrm{k})}\right)\right| \leq \mathrm{d}_{2 \mathrm{~m}(\mathrm{k})-1},
$$


$\left|\mathrm{d}\left(\mathrm{y}_{2 \mathrm{n}(\mathrm{k})+1}, \mathrm{y}_{2 \mathrm{~m}(\mathrm{k})-1}\right)-\mathrm{d}\left(\mathrm{y}_{2 \mathrm{n}(\mathrm{k})}, \mathrm{y}_{2 \mathrm{~m}(\mathrm{k})}\right)\right| \leq \mathrm{d}_{2 \mathrm{~m}(\mathrm{k})-1}+\mathrm{d}_{2 \mathrm{n}(\mathrm{k})}$,

and so, on using (3.9) we get

$$
\begin{aligned}
& \lim _{n \rightarrow \infty} \mathrm{d}\left(\mathrm{y}_{2 \mathrm{n}(\mathrm{k})}, \mathrm{y}_{2 \mathrm{~m}(\mathrm{k})-1}\right) \rightarrow \delta \\
& \lim _{n \rightarrow \infty} \mathrm{d}\left(\mathrm{y}_{2 \mathrm{n}(\mathrm{k})+1}, \mathrm{y}_{2 \mathrm{~m}(\mathrm{k})-1}\right) \rightarrow \delta
\end{aligned}
$$

as $\mathrm{k} \rightarrow \infty$. Thus

$$
\begin{array}{r}
\mathrm{d}\left(\mathrm{y}_{2 \mathrm{~m}(\mathrm{k})}, \mathrm{y}_{2 \mathrm{~m}(\mathrm{k})}\right) \leq \mathrm{d}_{2 \mathrm{n}(\mathrm{k})}+\mathrm{d}\left(\mathrm{y}_{2 \mathrm{n}(\mathrm{k})+1,}, \mathrm{y}_{2 \mathrm{~m}(\mathrm{k})}\right) \leq \mathrm{d}_{2 \mathrm{n}(\mathrm{k})} \\
+\mathrm{d}\left(\mathrm{S} x_{2 n(k)}, \mathrm{T} x_{2 m(k)-1}\right)
\end{array}
$$

Thus, on letting $\mathrm{k} \rightarrow \infty$, on both sides of the last inequality, we have

$$
\delta \leq \mathrm{d}\left(\mathrm{S} x_{2 n(k)}, \mathrm{T} x_{2 m(k)-1}\right) \leq \psi\left(\mathrm{M}\left(x_{2 n(k)}, x_{2 m(k)-1)}\right)\right.
$$

where

$$
\begin{aligned}
& \mathrm{M}\left(x_{2 n(k)}, x_{2 m(k)-1}\right)=\max \left\{\alpha _ { 1 } \left[\mathrm{d}\left(\mathrm{y}_{2 \mathrm{n}(\mathrm{k}),} \mathrm{y}_{2 \mathrm{~m}(\mathrm{k})-1}\right)+\mathrm{d}_{2 \mathrm{n}(\mathrm{k})+}\right.\right. \\
& \left.\mathrm{d}_{2 \mathrm{~m}(\mathrm{k})-1}\right]+\alpha_{2}\left[\mathrm{~d}\left(\mathrm{y}_{2 \mathrm{~m}(\mathrm{k})+1}, \mathrm{y}_{2 \mathrm{~m}(\mathrm{k})-1}\right)+\mathrm{d}\left(\mathrm{y}_{2 \mathrm{n}(\mathrm{k}),}, \mathrm{y}_{2 \mathrm{~m}(\mathrm{k})}\right)\right.
\end{aligned}
$$

Combining (3.5), (3.6), (3.7), (3.9), (3.11) and (3.12) yields the following contradiction from (3.14)

$$
\delta \leq \psi(\delta)<\delta
$$

Thus $\left\{\mathrm{y}_{2 \mathrm{n}}\right\}$ is a Cauchy sequence and so $\left\{\mathrm{y}_{\mathrm{n}}\right\}$ Cauchy sequence.

Suppose that TX is a complete subsequence of $\mathrm{X}$, then the sub sequence $\mathrm{y}_{\mathrm{n}}=\mathrm{T} \mathrm{x}_{2 \mathrm{n}+1}$ is a Cauchy sequence in TX and so have a limit $u$. Let $v \in T^{-1} u$, then $\mathrm{T} v=u$. since $\left\{\mathrm{y}_{2 \mathrm{n}}\right\}$ is convergent, so $\left\{y_{n}\right\}$ converges to $u$ and hence $\left\{y_{2 n+1}\right\}$ also converges to $u$. Now on setting $\mathrm{x}=\mathrm{x}_{2 \mathrm{n}}$ and $\mathrm{y}=v$, we get

$\mathrm{d}\left(\mathrm{Ax}_{2 \mathrm{n}}, \mathrm{B} v\right)<\max \left\{\alpha_{1}\left[\mathrm{~d}\left(\mathrm{Sx}_{2 \mathrm{n}}, \mathrm{T} v\right)+\mathrm{d}\left(\mathrm{Ax}_{2 \mathrm{n}}, \mathrm{Sx}_{2 \mathrm{n}}\right)+\mathrm{d}(\mathrm{B} v, \mathrm{~T} v)\right]+\right.$

$$
\left.\alpha_{2}\left[\mathrm{~d}\left(\mathrm{Sx}_{2 \mathrm{n}}, \mathrm{Bv}\right)+\mathrm{d}\left(\mathrm{Ax}_{2 \mathrm{n}}, \mathrm{Tv}\right)\right] / 2\right\}
$$

at $\mathrm{n} \rightarrow \infty$, we have $\mathrm{d}(u, \mathrm{~B} v)<\mathrm{d}(u, \mathrm{~B} v)$ which implies that $\mathrm{B} v=$ $u$. Also since $\mathrm{BX} \subset \mathrm{SX}$, so $u=\mathrm{B} v$ implies that $w \in \mathrm{S}^{-1} u$, then $\mathrm{d}\left(\mathrm{A} w, \mathrm{Bx}_{2 \mathrm{n}+1}\right)<\max \left\{\alpha_{1}\left[\mathrm{~d}\left(\mathrm{~S} w, \mathrm{Tx}_{2 \mathrm{n}+1}\right)+\mathrm{d}(\mathrm{A} w, \mathrm{~S} w)+\mathrm{d}\left(\mathrm{Bx}_{2 \mathrm{n}+1}\right.\right.\right.$,

$\left.\left.\left.\mathrm{Tx}_{2 \mathrm{n}+1}\right)\right]+\alpha_{2}\left[\mathrm{~d}\left(\mathrm{~S} w, \mathrm{Bx}_{2 \mathrm{n}+1}\right)+\mathrm{d}\left(\mathrm{A} w, \mathrm{Tx}_{2 \mathrm{n}+1}\right)\right] / 2\right\}$

at $\mathrm{n} \rightarrow \infty$, we have $\mathrm{d}(\mathrm{A} w, u)<\mathrm{d}(u, \mathrm{~A} w)$ which implies that $u$ $=\mathrm{A} w$. This makes clear that $u=\mathrm{T} v=\mathrm{B} v=\mathrm{A} w=\mathrm{S} w$

Now since $u=\mathrm{T} v=\mathrm{B} v$, so by weak compatibility of $(\mathrm{B}, \mathrm{T})$ it follows that $\mathrm{TB} v=\mathrm{BT} v$ and so we get $\mathrm{B} u=\mathrm{BT} v=\mathrm{TB} v=\mathrm{T} u$. Also since $u=\mathrm{A} w=\mathrm{S} w$ so by weak compatibility of $\mathrm{A}$ and $\mathrm{S}$ it follows that $\mathrm{SAw}=\mathrm{ASw}$ and so we get $\mathrm{A} u=\mathrm{AS} w=\mathrm{SA} w=\mathrm{S} u$. Thus from (3.3), we have

$\mathrm{d}(\mathrm{A} w, \mathrm{~B} u)<\max \left\{\alpha_{1}[\mathrm{~d}(\mathrm{~S} w, \mathrm{~T} u)+\mathrm{d}(\mathrm{A} w, \mathrm{~S} w)+\mathrm{d}(\mathrm{B} u, \mathrm{~T} u)]+\right.$

$$
\left.\alpha_{2}[\mathrm{~d}(\mathrm{~S} w, \mathrm{~B} u)+\mathrm{d}(\mathrm{A} w, \mathrm{~T} u)] / 2\right\}
$$

which gives $\mathrm{d}(u, \mathrm{~B} u)<\mathrm{d}(u, \mathrm{~B} u)$ which is a contradiction for $0 \leq$ $\alpha_{1}<1,1 \leq \alpha_{2}<2$, this implies that $u=\mathrm{B} u$. Similarly (3.3) can be used to show $\mathrm{A} u=u$. Therefore we have $u=\mathrm{B} u=\mathrm{T} u=\mathrm{A} u=$ $\mathrm{S} u$. Hence $u$ is the common fixed point of all A, B, S and T.
Now, if we assume SX is complete the argument analogue to the previous completeness argument, which proves the theorem. If $\mathrm{AX}$ is complete then $u \in \mathrm{BX} \subset \mathrm{SX}$. So the theorem is established. The uniqueness of the common fixed point follows easily from condition (3.3). This completes the proof of the theorem.

Lemma 3.1. $[10,12,20,21,22]$ Let $\mathrm{S}$ and $\mathrm{T}$ are compatible, compatible either of type (A), (type (P), type (B) or type (C)) self mappings of a metric space (X, d). If $\mathrm{S} u=\mathrm{T} u$ for some $u \in \mathrm{X}$, it follows that $\mathrm{ST} u=\mathrm{TS} u$.

From the previous theorem, our result is immediate.

Corollary 3.1. Let A, B, S and $\mathrm{T}$ be any self map of a metric space $(X, d)$ satisfying the conditions (1), (2) and (3) of Theorem 1. Now if pairs $\{A, S\}$ are compatible i.e. compatible of type (A), (type (P), type (B) or type (C), then the four maps having a unique common fixed point $u \in \mathrm{X}$.

Theorem 2: Let A, B, S and T be the selfmaps of a metric space $(X, d)$ satisfying the following conditions;

$(1) \mathrm{AX} \subset \mathrm{TX}, \mathrm{BX} \subset \mathrm{SX}$

(2) $\mathrm{d}(\mathrm{Ax}, \mathrm{By})<\max \left\{\alpha_{1}[\mathrm{~d}(\mathrm{Sx}, \mathrm{Ty})+\mathrm{d}(\mathrm{Ax}, \mathrm{Sx})+\mathrm{d}(\mathrm{By}, \mathrm{Ty})]+\right.$

$$
\left.\alpha_{2}[\mathrm{~d}(\mathrm{Sx}, \mathrm{By})+\mathrm{d}(\mathrm{Ax}, \mathrm{Ty})] / 2\right\}
$$

for $0 \leq \alpha_{1}<1, \quad 1 \leq \alpha_{2}<2$.

Let one of the mappings $(\mathrm{A}, \mathrm{S})$ or $(\mathrm{B}, \mathrm{S})$ be weakly compatible, satisfying property (E.A.). If the range of one of the mappings be a complete subspace of $\mathrm{X}$, then $\mathrm{A}, \mathrm{B}, \mathrm{S}$ and $\mathrm{T}$ have a unique common fixed point.

Proof: Let $\mathrm{B}$ and $\mathrm{T}$ satisfy property E.A. Then there exists a sequence $\left\{x_{n}\right\}$ in $\mathrm{X}$ such that $\mathrm{B} x_{n} \rightarrow \mathrm{t}$ and $\mathrm{T} x_{n} \rightarrow \mathrm{t}$ for some $\mathrm{t}$ in $\mathrm{X}$. Since $\mathrm{BX} \subset \mathrm{SX}$, for each $x_{n}$, there exists $y_{n}$ in $\mathrm{X}$, such that $\mathrm{B} x_{n}=\mathrm{S} y_{n}$. Thus $\mathrm{B} x_{n} \rightarrow \mathrm{t}, \mathrm{T} x_{n} . \rightarrow \mathrm{t}$ and S $y_{n} \rightarrow \mathrm{t}$. We claim that A $y_{n} \rightarrow$ t. If not, there exists a sub sequence $\left\{\mathrm{A} y_{m}\right\}$ of $\left\{\mathrm{A} y_{n}\right)$, a positive integer $\mathrm{M}$ and a number $\mathrm{r}>0$ such that for each $\mathrm{m} \geq \mathrm{M}$, we have

$\mathrm{d}\left(\mathrm{A} y_{m}, \mathrm{t}\right) \geq \mathrm{r}, \mathrm{d}\left(\mathrm{A} y_{m}, \mathrm{~B} x_{m}\right) \geq \mathrm{r}$,

$\mathrm{d}\left(\mathrm{A} y_{m}, \mathrm{~B} x_{m}\right)<\max \left\{\alpha_{1}\left[\mathrm{~d}\left(\mathrm{~S} y_{m}, \mathrm{~T} x_{m}\right)+\mathrm{d}\left(\mathrm{A} y_{m}, \mathrm{~S} y_{m}\right)+\right.\right.$

$\left.\left.\mathrm{d}\left(\mathrm{B} x_{m}, \mathrm{~T} x_{m}\right)\right]+\alpha_{2}\left[\mathrm{~d}\left(\mathrm{~A} y_{m}, \mathrm{~T} x_{m}\right)+\mathrm{d}\left(\mathrm{B} x_{m}, \mathrm{~S} y_{m}\right)\right] / 2\right\}$

$$
<\mathrm{d}\left(\mathrm{A} y_{m}, \mathrm{~S} y_{m}\right)
$$

a contradiction. Hence A $y_{n} \rightarrow \mathrm{t}$. Now suppose that $\mathrm{SX}$ is a complete subspace of $\mathrm{X}$. Then, since $\mathrm{S} y_{n} \rightarrow \mathrm{t}$, there exists a point $\mathrm{u}$ in $\mathrm{X}$. Such that $\mathrm{t}=\mathrm{S} u$. If $\mathrm{A} u \neq \mathrm{S} u$, the inequality.

$\mathrm{d}\left(\mathrm{A} u, \mathrm{~B} x_{n}\right)<\max \left\{\alpha_{1}\left[\mathrm{~d}\left(\mathrm{~S} u, \mathrm{~T} x_{n}\right)+\mathrm{d}(\mathrm{A} u, \mathrm{~S} u)+\mathrm{d}\left(\mathrm{B} x_{n}, \mathrm{~T} x_{n}\right)\right]+\right.$

$$
\left.\alpha_{2}\left[\mathrm{~d}\left(\mathrm{~A} u, \mathrm{~T} x_{n}\right)+\mathrm{d}\left(\mathrm{B} x_{n}, \mathrm{~S} u\right)\right] / 2\right\}
$$

On taking $\mathrm{n} \rightarrow \infty$, yields $\mathrm{d}(\mathrm{Au}, \mathrm{Su})<\mathrm{d}(\mathrm{Au}, \mathrm{Su})$, a 
contradiction. Hence $\mathrm{A} u=\mathrm{S} u$. Since $\mathrm{A}$ and $\mathrm{S}$ are weakly compatible so it implies that $\mathrm{AS} u=\mathrm{SA} u$ and so $\mathrm{A} u=\mathrm{AS} u=\mathrm{SA} u$ $=\mathrm{S} u$.

On the other hand, since $\mathrm{AX} \subset \mathrm{TX}$, there exists a point $\mathrm{w} \in \mathrm{X}$, such that $\mathrm{A} u=\mathrm{T} w$. We assert that $\mathrm{T} w=\mathrm{B} w$. If $\mathrm{B} w \neq \mathrm{T} w$, then by (2) we get

$\mathrm{d}(\mathrm{A} u, \mathrm{~B} w)<\max \left\{\alpha_{1}[\mathrm{~d}(\mathrm{~S} u, \mathrm{~T} w)+\mathrm{d}(\mathrm{A} u, \mathrm{~S} u)+\mathrm{d}(\mathrm{B} w, \mathrm{~T} w)]+\right.$

$$
\left.\alpha_{2}[\mathrm{~d}(\mathrm{~A} u, \mathrm{~T} w)+\mathrm{d}(\mathrm{B} w, \mathrm{~S} u)] / 2\right\}
$$

$<\mathrm{d}(\mathrm{B} w, \mathrm{~A} u)$

a contradiction. Hence $\mathrm{A} u=\mathrm{B} w=\mathrm{T} w=\mathrm{S} u$, which shows that the pairs $(\mathrm{A}, \mathrm{S})$ and $(\mathrm{B}, \mathrm{T})$ have a point of coincidence $u$ and $w$, respectively. The proof is similar if we consider the case when pair (A, S) enjoys prorperty (E.A).

Now by weak compatibility property of $\mathrm{B}$ and $\mathrm{T}$, it implies that $\mathrm{BT} w=\mathrm{TB} w$ and. $\mathrm{BB} w=\mathrm{BT} w=\mathrm{TB} w=\mathrm{TT} w$. Suppose that $\mathrm{A} u \neq \mathrm{AA} u$. So we have from (3.22),

$\mathrm{d}(\mathrm{A} u, \mathrm{AA} u)=\mathrm{d}(\mathrm{AA} u, \mathrm{~B} w)<\max \left\{\alpha_{1}[\mathrm{~d}(\mathrm{SA} u, \mathrm{~T} w)+\right.$

$$
\left.\mathrm{d}(\mathrm{AA} u, \mathrm{SA} u)+\mathrm{d}(\mathrm{B} w, \mathrm{~T} w)]+\alpha_{2}[\mathrm{~d}(\mathrm{AA} u, \mathrm{~T} w)+\mathrm{d}(\mathrm{B} w, \mathrm{SA} u)] / 2\right\}
$$

$$
<\mathrm{d}(\mathrm{AA} u, \mathrm{~A} u) \text {. }
$$

which is a contradiction. Thus $\mathrm{A} u=\mathrm{AA} u=\mathrm{SA} u$ and $\mathrm{A} u$ is a common fixed point of $\mathrm{A}$ and $\mathrm{S}$. Similarly $\mathrm{A} u=\mathrm{B} w$ is a common fixed point of $\mathrm{B}$ and $\mathrm{T}$. The proof is similar when TX is assumed to be complete subspace of $\mathrm{X}$. The cases in which $\mathrm{AX}$ or $\mathrm{BX}$ is a complete subspace of $\mathrm{X}$ are similar to the cases in which TX or $\mathrm{SX}$ respectively be complete since $\mathrm{AX} \subset \mathrm{TX}$ and $\mathrm{BX} \subset \mathrm{SX}$. The uniqueness of the common fixed point follows easily from (3.22). Hence the theorem.

We now illustrate the above theorem by the way of the following example.

Example 4. Let $X=[0,1]$ and $d$ be the usual metric on $X$. Define A, B, S and T: $\mathrm{X} \rightarrow \mathrm{X}$ by

$\mathrm{Ax}=\mathrm{Bx}=0$, if $\mathrm{x}=0$ or $\mathrm{x}=1, \mathrm{Ax}=\mathrm{Bx}=\frac{1}{n+2}$, if

$\frac{1}{n+2} \leq \mathrm{x}<\frac{1}{n}, \mathrm{n} \in \mathrm{N} ;$ and $\mathrm{SX}=\mathrm{Tx}=\mathrm{x} \quad \forall \mathrm{x} \in \mathrm{X}$.

Here (A,S) satisfies property (E.A). Taking $\left\{\frac{1}{n+2}\right\} \subseteq$

$[0,1]$, we get $\lim _{n \rightarrow \infty} \mathrm{A}\left(\frac{1}{n+2}\right)=\lim _{n \rightarrow \infty}\left(\frac{1}{n+2}\right)=0=$ $\lim _{n \rightarrow \infty} S\left(\frac{1}{n+2}\right)=\lim _{n \rightarrow \infty}\left(\frac{1}{n+2}\right)$.

Similarly, (B, T) satisfies property (E.A.).

Then A, B, S and T satisfy all the conditions of above Theorem 2. It can be verified in this example that $B$ and $T$ are weakly compatible type, since $\mathrm{A} x=\mathrm{S} x$, occurs if $\mathrm{x}=0$ or $\mathrm{x}=$ $\frac{1}{n+2}, \mathrm{n} \in \mathrm{N}$.Here we have, $\operatorname{AS}(0)=\mathrm{A} 0=0=\mathrm{S} 0=\mathrm{SA}(0)$ and $\operatorname{AS}\left(\frac{1}{n+2}\right)=\mathrm{A}\left(\frac{1}{n+2}\right)=\frac{1}{n+2}=\mathrm{S}\left(\frac{1}{n+2}\right), \mathrm{n} \in \mathrm{N}$.
Similarly $(\mathrm{B}, \mathrm{T})$ is weakly compatible.

Theorem 3: Let A, B, S and T be weakly compatible selfmaps of a metric space $(\mathrm{X}, \mathrm{d})$ satisfying the following conditions;

(1) $\mathrm{AX} \subset \mathrm{TX}, \mathrm{BX} \subset \mathrm{SX}$

(2) $\mathrm{d}(\mathrm{Ax}, \mathrm{By})<\max \left\{\alpha_{1}[\mathrm{~d}(\mathrm{Sx}, \mathrm{Ty})+\mathrm{d}(\mathrm{Ax}, \mathrm{Sx})+\mathrm{d}(\mathrm{By}, \mathrm{Ty})]\right.$

$$
\begin{aligned}
&\left.+\alpha_{2}[\mathrm{~d}(\mathrm{Sx}, \mathrm{By})+\mathrm{d}(\mathrm{Ax}, \mathrm{Ty})] / 2\right\} \\
& \text { for } 0 \leq \alpha_{1}<1, \quad 1 \leq \alpha_{2}<2
\end{aligned}
$$

Let one of the mappings (A, S) or $(\mathrm{B}, \mathrm{S})$ be noncompatible, satisfying property (E.A). If the range of one of the mappings be a complete subspace of $\mathrm{X}$, then $\mathrm{A}, \mathrm{B}, \mathrm{S}$ and $\mathrm{T}$ have a unique common fixed point and the fixed point is a point of discontinuity.

Proof: Suppose that $\mathrm{B}$ and $\mathrm{T}$ be noncompatible maps, so there exists a sequence $\left\{x_{n}\right\}$ in $\mathrm{X}$ such that

$\lim _{n \rightarrow \infty} \mathrm{B} x_{n}=\mathrm{t}$ and $\lim _{n \rightarrow \infty} \mathrm{T} x_{n}=\mathrm{t}$

for some $\mathrm{t} \in \mathrm{X}$, but $\lim _{n \rightarrow \infty} \mathrm{d}\left(\mathrm{BT} x_{n}, \operatorname{TB} x_{n}\right)$ is either nonzero or nonexistent. Since BX $\subset \mathrm{SX}$, for each $x_{n}$, there exists a $y_{n}$ $\in \mathrm{X}$, such that $\mathrm{B} x_{n}=\mathrm{S} y_{n}$. Thus $\mathrm{B} x_{n} \rightarrow \mathrm{t}, \mathrm{T} x_{n} . \rightarrow \mathrm{t}$ and $\mathrm{S} y_{n} \rightarrow \mathrm{t}$. We claim that $\mathrm{A} y_{n} \rightarrow \mathrm{t}$. If not, there exists a subsequence $\left\{\mathrm{A} y_{m}\right\}$ of $\left\{\mathrm{A} y_{n}\right.$ ), a positive integer $\mathrm{M}$ and a number $\mathrm{r}>0$ such that for each $\mathrm{m} \geq \mathrm{M}$, we have

$\mathrm{d}\left(\mathrm{A} y_{m}, \mathrm{t}\right) \geq \mathrm{r}, \mathrm{d}\left(\mathrm{A} y_{m}, \mathrm{~B} x_{m}\right) \geq \mathrm{r}$,

$\mathrm{d}\left(\mathrm{A} y_{m}, \mathrm{~B} x_{m}\right)<\max \left\{\alpha_{1}\left[\mathrm{~d}\left(\mathrm{~S} y_{m}, \mathrm{~T} x_{m}\right)+\mathrm{d}\left(\mathrm{A} y_{m}, \mathrm{~S} y_{m}\right)\right.\right.$

$\left.\left.+\mathrm{d}\left(\mathrm{B} x_{m}, \mathrm{~T} x_{m}\right)\right]+\alpha_{2}\left[\mathrm{~d}\left(\mathrm{~A} y_{m}, \mathrm{~T} x_{m}\right)+\mathrm{d}\left(\mathrm{B} x_{m}, \mathrm{~S} y_{m}\right)\right] / 2\right\}$

$$
<\mathrm{d}\left(\mathrm{A} y_{m}, \mathrm{~S} y_{m}\right)
$$

a contradiction. Hence A $y_{n} \rightarrow$ t. Suppose that SX is a complete subspace of $\mathrm{X}$. Then since $\mathrm{S} y_{n} \rightarrow \mathrm{t}$, there exists a point $\mathrm{u}$ in $\mathrm{X}$. Such that $\mathrm{t}=\mathrm{S} u$. If $\mathrm{A} u \neq \mathrm{S} u$, the inequality.

$\mathrm{d}\left(\mathrm{A} u, \mathrm{~B} x_{n}\right)<\max \left\{\alpha_{1}\left[\mathrm{~d}\left(\mathrm{~S} u, \mathrm{~T} x_{n}\right)+\mathrm{d}(\mathrm{A} u, \mathrm{~S} u)+\mathrm{d}\left(\mathrm{B} x_{n}, \mathrm{~T} x_{n}\right)\right]\right.$

$$
\left.+\alpha_{2}\left[\mathrm{~d}\left(\mathrm{~A} u, \mathrm{~T} x_{n}\right)+\mathrm{d}\left(\mathrm{B} x_{n}, \mathrm{~S} u\right)\right] / 2\right\}
$$

on taking $\mathrm{n} \rightarrow \infty$, yields $\mathrm{d}(\mathrm{A} u, \mathrm{~S} u)<[\mathrm{d}(\mathrm{A} u, \mathrm{~S} u)]$ a contradiction. Hence $\mathrm{A} u=\mathrm{S} u$. Since $\mathrm{A}$ and $\mathrm{S}$ are weakly compatible so it implies that $\mathrm{AS} u=\mathrm{SA} u$ and then $\mathrm{AA} u=\mathrm{AS} u=$ $\mathrm{SA} u=\mathrm{SS} u$.

On the other hand, since $\mathrm{AX} \subset \mathrm{TX}$, there exists a point $w \in \mathrm{X}$, such that $\mathrm{A} u=\mathrm{T} w$. We assert that $\mathrm{T} w=\mathrm{B} w$. If $\mathrm{B} w \neq \mathrm{T} w$, then by (3.30) we get

$\mathrm{d}(\mathrm{A} u, \mathrm{~B} w)<\max \left\{\alpha_{1}[\mathrm{~d}(\mathrm{~S} u, \mathrm{~T} w)+\mathrm{d}(\mathrm{A} u, \mathrm{~S} u)+\mathrm{d}(\mathrm{B} w, \mathrm{~T} w)]\right.$

$$
\left.+\alpha_{2}[\mathrm{~d}(\mathrm{~A} u, \mathrm{~T} w)+\mathrm{d}(\mathrm{B} w, \mathrm{~S} u)] / 2\right\}
$$

$<\mathrm{d}(\mathrm{B} w, \mathrm{~A} u)$ 
a contradiction. Hence $\mathrm{A} u=\mathrm{S} u=\mathrm{B} w=\mathrm{T} w$, which sh pairs $(\mathrm{A}, \mathrm{S})$ and $(\mathrm{B}, \mathrm{T})$ have a point of coinciden respectively. The proof is similar if we consider the case when pair (A, S) enjoys prorperty (E.A).

Now by weak compatibility property of $\mathrm{B}$ and $\mathrm{T}$, it implies that $\mathrm{BT} w=\mathrm{TB} w$ and $\mathrm{BB} w=\mathrm{BT} w=\mathrm{TB} w=\mathrm{TT} w$. Now, suppose that $\mathrm{A} u \neq \mathrm{AA} u$. So we have from (3.30)

$\mathrm{d}(\mathrm{A} u, \mathrm{AA} u)=\mathrm{d}(\mathrm{AA} u, \mathrm{~B} w)$

$$
\begin{gathered}
<\max \left\{\alpha_{1}[\mathrm{~d}(\mathrm{SA} u, \mathrm{~T} w)+\mathrm{d}(\mathrm{AA} u, \mathrm{SA} u)+\mathrm{d}(\mathrm{B} w, \mathrm{~T} w)]\right. \\
\left.+\alpha_{2}[\mathrm{~d}(\mathrm{AA} u, \mathrm{~T} w)+\mathrm{d}(\mathrm{B} w, \mathrm{SA} u)] / 2\right\}
\end{gathered}
$$

$<\mathrm{d}(\mathrm{AA} u, \mathrm{~A} u)$.

which is a contradiction. Thus $\mathrm{A} u=\mathrm{AA} u=\mathrm{SA} u$, then $\mathrm{A} u$ is a common fixed point of A and S. Similarly $\mathrm{A} u=\mathrm{B} w$ is a common fixed point of $B$ and $T$. The proof is similar when TX is assumed to be complete subspace of $\mathrm{X}$. The cases in which $\mathrm{AX}$ or $\mathrm{BX}$ is a complete subspace of $\mathrm{X}$ are similar to the cases in which TX or $\mathrm{SX}$ respectively be complete since $\mathrm{AX} \subset \mathrm{TX}$ and $\mathrm{BX} \subset \mathrm{SX}$. Uniqueness of the common fixed point follows easily.

We have to show now that the mappings are discontinuous at the common fixed point. Let us suppose that B is continuous at common fixed point $\mathrm{t}$, such that $t=\mathrm{Au}=\mathrm{B} w$. So on taking the sequence $\left\{x_{n}\right\}$ as taken in (3.30), we have $\lim _{n \rightarrow \infty} \mathrm{BB} x_{n}=\mathrm{B} t=t$ and $\lim _{n \rightarrow \infty} \mathrm{BT} x_{n}=\mathrm{B} t=t$. By weak compatibility property of $\mathrm{B}$ and T, it follows that BT $x_{n}=\operatorname{TB} x_{n}$. On letting $n \rightarrow \infty$, this gives us $\lim _{n \rightarrow \infty} \mathrm{BT} x_{n}=\lim _{n \rightarrow \infty} \mathrm{TB} x_{n}=\mathrm{B} t=t$. Thus, we get $\mathrm{d}\left(\mathrm{BT} x_{n}\right.$, $\left.\mathrm{TB} x_{n}\right)=\mathrm{d}(\mathrm{Bt}, \mathrm{Bt})=0$, which contradicts the fact that $\lim _{n \rightarrow \infty} \mathrm{d}\left(\mathrm{BT} x_{n}, \operatorname{TB} x_{n}\right)$ is either nonzero or nonexistent for the sequence $\left\{x_{n}\right\}$ of (3.30). Hence B is discontinuous at the fixed point. Now, suppose that $\mathrm{T}$ is continuous, then for the sequence $\left\{x_{n}\right\}$ of (3.30), we get $\lim _{n \rightarrow \infty} \mathrm{TB} x_{n}=\mathrm{Tt}=\mathrm{t}$ and $\lim _{n \rightarrow \infty} \mathrm{TT} x_{n}=\mathrm{T} t=$ $t$. Hence, the inequality, in view of these limits, gives us; $\mathrm{d}\left(\right.$ At, BT $\left.x_{n}\right)<\max \left\{\alpha_{1}\left[\mathrm{~d}\left(\mathrm{St}, \mathrm{TT} x_{n}\right)+\mathrm{d}(\mathrm{At}, \mathrm{St})+\right.\right.$

$$
\left.\left.\mathrm{d}\left(\mathrm{BT} x_{n}, \text { TT } x_{n}\right)\right]+\alpha_{2}\left[\mathrm{~d}\left(\mathrm{At}, \mathrm{TT} x_{n}\right)+\mathrm{d}\left(\mathrm{BT} x_{n}, \mathrm{St}\right)\right] / 2\right\}
$$

which gives contradiction, unless $\lim _{n \rightarrow \infty} \mathrm{BT} x_{n}=\mathrm{TT} x_{n}=\mathrm{Tt}=\mathrm{t}$.

But $\lim _{n \rightarrow \infty} \mathrm{BT} x_{n}=\mathrm{Tt}=\mathrm{t}$. and $\lim _{n \rightarrow \infty} \mathrm{TB} x_{n}=\mathrm{T} t=t$ which contradicts the fact that $\mathrm{d}\left(\mathrm{BT} x_{n}\right.$, $\left.\operatorname{TB} x_{n}\right)$ is either nonzero

or nonexistent. Hence, both $\mathrm{B}$ and $\mathrm{T}$ are discontinuous at their common fixed point. Likewise, it can be shown that $\mathrm{A}$ and $\mathrm{S}$ are also discontinuous at the common fixed point. Thus all the selfmaps $\mathrm{A}, \mathrm{B}, \mathrm{S}$ and $\mathrm{T}$ are discontinuous at the common fixed point. Hence, the theorem is established.

Our example is motivated by example of Pant [17].
Example 5. Let $X=[1,20]$ and $d$ be the usual metric on $X$. Define A, B, S, T:X $\rightarrow X$ by

$\mathrm{Ax}=\left\{\begin{array}{l}1 \text { if }, x=1 \\ 3 \text { if }, x>1\end{array} \quad \mathrm{Bx}=\left\{\begin{array}{l}1 \text { if }, x=1 \text { or } \geq 5 \\ 6 \text { if }, 1<x<5\end{array}\right.\right.$
$\mathrm{Sx}=\left\{\begin{array}{l}1 \text { if }, x=1 \\ 6 \text { if }, x>1\end{array} \quad \mathrm{Tx}=\left\{\begin{array}{l}7+x \text { if }, 1<x<5 \\ x+1 \text { if }, x \geq 5\end{array}\right.\right.$

$\mathrm{T} 1=1$

Then A, B, S and T satisfy all the conditions of above Theorem 2 and have a unique common fixed point $\mathrm{x}=1$. It can be verified in this example that B and T satisfy the property (E.A). Also, it can be seen that all the mappings $\mathrm{A}, \mathrm{B}, \mathrm{S}$ and $\mathrm{T}$ are discontinuous at the common fixed point.

\section{CONCLUSION}

In this paper, we have proved the common fixed point theorems for four mappings by removing the assumption of continuity, relaxing the compatibility to weak compatibility property and also replacing the completeness of space. So our result generalizes and improves various other similar results of fixed point. Besides this, we have used a new property, introduced by Aamri and Moutawakil [1], satisfying selfmaps of a metric space, which generalize the notion of noncompatible maps.

\section{REFERENCES}

[1] M.Aamri and D.El.Moutawkil, Some new common fixed point theorems under strict contractive conditions, J.Math.Anal.Appl., 270(1); 181-188,(2002).

[2] C.D.Bari and C.Vetro, Common fixed point for weakly compatible maps satisfying a general contractive condition, Int.J.Math.Math.Sci. Vol 2008.Art. ID 891375, 8 pages.

[3] H.Bouhadjera, General common fixed point theorems for compatible mappings of type (C), Sarajevo J.Math.Vol.1 (14), (2005), 261-270.

[4] H.Bouhadjera and A.Djoudi, General common fixed point theorem for weakly compatible maps, Gen.Mathematics. Vol.16 no.2 (2008), 95-107.

[5] D.W.Boyd and J.S.Wong, On non linear contractions, Proc.Amer.Math.Soc. 20(1969), 458-464.

[6] A.Carbone, B.E.Rhoades and S.P.Singh, A fixed point theorem for generalized contraction map, Indian J.Pure and Appl. Math.20 (1969), 543-548.

[7] J.Jachymski, Common fixed point theorems for some families of maps, Indian J.Pure and Appl. Math.25 (1994), no.9, 925-937.

[8] K.Jha, R.P.Pant, and S.L.Singh, Common fixed points for compatible mappings on metric spaces, Rad.Math.12 (2003), no.1, 107-114.

[9] K.Jha, R.P.Pant, and S.L.Singh, On existence of common fixed point for compatible mappings, J.Math (ISSN 10162526), Vol.37 (2005), 37-48. 
[10] G.Jungck, Compatible mappings and common fixed points, Int.J.Math.Math. Sci. 9 (1986), 771-779.

[11] G.Jungck, Common fixed point for noncontinous non selfmaps on nonmetric spaces, Far East.J.Math.Sci. 4(2), (1996), 199-215.

[12] G.Jungck, P.P.Murthy and Y.J.Cho, Compatible mappings of type (A) and Common fixed points, Math,Japonica, 38(2), (1993), 381-390.

[13] G.Jungck, K.B.Moon, S.Park and B.E.Rhoades, On generalizations of Meir Keeler type contractive maps corrections, J.Math.Anal.Appl.180 (1993), 221-222.

[14] G.Jungck and B.E.Rhoades, Fixed point for set valued functions without continuity, Indian J.Pure Appl. Math. 29(3), (1998), 227-238.

[15] A.Meir and E.Keeler, A theorem on contractive maps, J.Math.Anal.Appl, 28 (1969), 326-329.

[16] R.P.Pant, Common fixed point of contractive maps, J.Math.Anal.Appl. 226(1998), 251-258.

[17] R.P.Pant, Discontinuity and fixed points, J.Math.Anal.Appl.240 (1), (1999), 284-289.
[18] R.P.Pant, P.C.Joshi, and V.Gupta, A Meir Keeler type fixed point theorem, Indian J.Pure Appl.Math, 32 (6) (2001), 779787.

[19] S.Park and B.E.Rhoades, Extensions of fixed point theorem of Meir Keeler, Ark.Math. 19 (1991), 223-238.

[20] H.K.Pathak and M.S.Khan, Compatible mappings of type (B) and common fixed point of Gregus type, Czechoslovak Math.J. 45 9120), (1995), 685-698.

[21] H.K.Pathak, Y.J.Cho, S.M.Khan and B.S.Lee, Compatible mappings of type $(\mathrm{P})$ and its applications to dynamic programming, Lee Mathematiche, 50(1995), Fasc. 1, 15-30.

[22] H.K.Pathak, Y.J.Cho, S.M.Khan and B.S.Madharia, Compatible mappings of type (C) and common fixed point theorem of Gregus type, Demonstratio Math. J. 31, (1998), no. $3,499-518$.

[23] S.Sessa, On weak commutativity conditions of mappings in fixed point considerations, Pub.Inst.Math.32 (1998), 149153.

[24] S.L.Singh and A.Tomar, Weaker forms of commuting maps and existence of fixed pints, J.Korean.Soc.Math.Edu.Ser.B.PureAppl.Math.Vol.10 (3), (2003), 145- 161. 